\title{
Tecnologia digital e aprendizado da língua portuguesa entre imigrantes $e$ refugiados no Brasil
}

SANZOVO, Claudia Cristina. Tecnologia digital e aprendizado da língua portuguesa entre imigrantes refugiados no Brasil. Entrepalavras, Fortaleza, v. 11, n. 3, e2199, p. 75-89, set.-dez./2021. DOI: 10.22168/22376321-32199.

Digital technology and learning of portuguese language among immigrants and refugees in Brazil

\section{Claudia Cristina SANZOVO (UNICESUMAR)} tizia8@hotmail.com

Recebido em: 07 de jan. de 2021. Aceito em: 20 de jun. de 2021.
Resumo: O presente estudo, de caráter qualitativo exploratório, tem como objetivo apresentar dados relativos às ferramentas tecnológicas digitais utilizadas por imigrantes e refugiados residentes no Brasil no aprendizado/ prática da língua portuguesa de acolhimento. Considerando a língua como a base para a comunicação e a integração social, o estudo destaca como referenciais teórico-epistemológicos as questões migratórias e da língua de acolhimento em Milesi e Andrade (2015), Barbosa e São Bernardo (2017), a língua e a aprendizagem em Stern (1983), Cassany (1999), Oliveira (2010), Silva (2012) e Paterson (2012), os letramentos em Kleiman (2005) e as tecnologias digitais em Kenski (2012), Prensky (2010) e Selwyn (2017) e, a partir dos dados coletados por meio de um questionário de pesquisa aplicado em onze comunidades de migrantes no Facebook, destaca-se como resultado que a maioria dos pesquisados possuem um nível de escolaridade elevado em seus países de origem, mas apresentam dificuldades com a aprendizagem da gramática e com as variações linguísticas da língua portuguesa, principalmente, por indicarem, na sua maioria, que o 
V. $11(3)$ 75-89 set-dez 2021 aprendizado/prática ocorre no ambiente familiar, no trabalho e na internet (Duolingo, Youtube, Facebook, Instagram), o que evidencia a carência de cursos formais específicos da língua portuguesa de acolhimento (Plac).

Palavras-chave: Tecnologia digital. Língua portuguesa. Migrantes.

\begin{abstract}
The present study and its exploratory qualitative nature, aims to present a profile of immigrants and refugees related to the digital technological tools used by them in learning/practising the Brazilian Portuguese language. Considering language as the basis for communication and social integration, the study highlights as theoretical and epistemological references: the migratory and host language issues in Milesi and Andrade (2015), Barbosa and São Bernardo (2017), language and learning in Stern (1983), Cassany (1999), Oliveira (2010), Silva (2012), and Paterson (2012), literacy in Kleiman (2005), digital technologies in Kenski (2012), Prensky (2010), Selwyn (2017) and, based on the data collected through a research questionnaire applied to eleven migrant communities on Facebook, we highlight as a result that most of them have a high level of education in their countries of origin, but have difficulties in learning grammar and linguistic variations of Portuguese language, mainly because they indicate that learning / practice occurs in the family, work and on the internet (Duolingo, Youtube, Facebook, Instagram) environments, what demonstrate the lack of formal courses in the host language.
\end{abstract}

Keywords: Digital Technology. Portuguese language. Migrants.

\title{
Introdução
}

O estudo em questão surgiu a partir da observação do cotidiano de imigrantes e refugiados que vivem atualmente no Brasil e da problemática em relação ao aprendizado da língua portuguesa nesses grupos. Em diversos estabelecimentos comerciais, nos ônibus, nas escolas, igrejas e universidades, frequentemente encontramos pessoas com distintos sotaques e percebemos que, dentre elas, encontram-se migrantes ${ }^{1}$ que enfrentam dificuldades em se comunicar e escrever em língua portuguesa. Além disso, é notável que esses migrantes estão constantemente utilizando seus aparelhos celulares em conversas com seus familiares e amigos por meio das redes sociais.

A partir dessas constatações iniciais, surgiu a motivação de realizar esta pesquisa com o objetivo principal de traçar um perfil dos migrantes em relação aos meios digitais utilizados no aprendizado/

\footnotetext{
${ }^{1}$ Não há uma definição universalmente aceita para "migrantes", no entanto, para este estudo, não implicando qualquer nova categoria legal mas simplesmente como um sinônimo de imigrantes e refugiados, utilizaremos a definição da Organização Internacional para as Migrações (OIM) de qualquer pessoa que se muda de seu local de residência habitual através de uma fronteira internacional, temporária ou permanentemente, e por uma variedade de razões. O termo inclui várias categorias jurídicas bem definidas de pessoas, como trabalhadores migrantes; pessoas cujos tipos específicos de movimentos são legalmente definidos, como migrantes contrabandeados; bem como aqueles cujo status ou meio de movimento não são especificamente definidos pelo direito internacional, como estudantes internacionais.
} 
prática ${ }^{2}$ da língua portuguesa. Como objetivos específicos busca-se: (i) destacar suas principais dificuldades em relação à língua portuguesa, (ii) analisar as características e os conhecimentos linguísticos prévios desses migrantes, (iii) elencar as ferramentas tecnológicas utilizadas pelos sujeitos de pesquisa no processo de aprendizagem/prática da leitura e escrita na língua portuguesa, (iv) apontar a necessidade de criação de cursos formais para o ensino-aprendizagem da língua portuguesa de acolhimento (Plac).

O estudo de caráter qualitativo busca explorar os aspectos da língua de acolhida nas práticas cotidianas de letramento dos migrantes, dentro de uma perspectiva na qual as relações interculturais possam ser mais inclusivas, acolhendo também as variedades da língua portuguesa e os meios digitais como ferramentas de prática e aprendizagem. $\mathrm{O}$ estudo justifica-se pela importância social que o domínio de uma língua possui no contexto migratório, pelas questões de afetividade, instrumentalismo e pelas diferentes tecnologias digitais que podem auxiliar nesse processo de aprendizagem/prática.

Com relação à organização, o presente estudo será dividido em três partes: a primeira contempla as questões migratórias e a tecnologia na aprendizagem/prática da língua portuguesa de acolhimento; a segunda apresenta a metodologia utilizada para a pesquisa e a terceira engloba a análise dos dados, seguida pelas considerações finais sobre o tema.

\section{Questões migratórias e a tecnologia digital na aprendizagem/prática da língua portuguesa de acolhimento}

As discussões sobre a temática migratória são constantes e podem ser analisadas de maneira transversal por diversos ângulos como: político, econômico, cultural, educacional, entre outros. No que tange ao ensino/aprendizagem ${ }^{3}$ da língua portuguesa de acolhimento no Brasil e o intercâmbio cultural dos imigrantes, os dados da ACNUR et al. (2019) indicam que o fluxo migratório

\footnotetext{
${ }^{2}$ Consideramos que o termo aprendizagem refere-se ao ato de aprender o que, de acordo com Kubo e Botomé (2001), não necessariamente precisa do auxílio de um professor e à prática como um hábito de realização costumeira de atividades individuais relacionados a esse aprendizado, como a leitura de textos, a escrita e as conversas orais em distintos contextos.

3 Aqui os substantivos "ensino" e "aprendizagem" fazem referência ao processo de "ensinar" e "aprender" que, de acordo com Kubo e Botomé (2001), constitui fundamentalmente um complexo sistema de interações comportamentais entre professores e alunos (pelo menos no caso de "ensinar", uma vez que é possível "aprender" sem um professor).
} 
V. $11(3)$ 75-89 set-dez 2021

atual provém de países como a Síria, o Sudão do Sul, a Venezuela e Honduras, além de comprovarem que as instituições sociais (escolas, igrejas, associações, clubes, ONG's, etc.) e a tecnologia digital possuem um papel importante no processo de inserção social e econômica desses cidadãos. Tanto que, em se tratando das tecnologias digitais, as organizações internacionais estão "investindo recursos consideráveis para explorar de que maneira a onipresença e a rápida expansão da funcionalidade das tecnologias móveis podem ser aproveitadas para promover a aprendizagem" (UNESCO, 2014, p. 44).

Dados recentes divulgados pela Organização das Nações Unidas (ONU) indicam que o mundo tem cerca de 250 milhões de migrantes internacionais que vivem em países distintos dos que nasceram. Desse total, segundo a ACNUR et al. (2019, p.6), mais de 68 milhões encontram-se em situação de deslocamento forçado ao deixarem seus países de origem para requerer uma proteção internacional devido a um fundado temor de perseguição e risco de violência, caso voltem para suas casas.

Apesar dos números crescentes de migrantes a nível mundial, de acordo com a ACNUR et al. (2019), no Brasil eles correspondem a menos de $1 \%$ do total da população, mesmo que o país receba atualmente um fluxo migratório considerável de pessoas oriundas de diversos países do mundo, principalmente, de seus vizinhos venezuelanos, colombianos, bolivianos, uruguaios, argentinos, assim como de haitianos e refugiados de países dos continentes africano e asiático.

No contexto dessas migrações e no âmbito do Estado português, surge o termo "língua de acolhimento", usada em seu sentido literal de "acolhida, refúgio em casa, forte, cidade, praça" (ANÇÂ, 2005, p. 1). Esse termo, conforme problematiza Anunciação (2018, p. 45), não pode ser simplesmente transposto para a realidade migratória brasileira, justamente porque "seus pressupostos se baseiam na ideia de um multiculturalismo liberal", que reforça o mito e a ideologia de um país monolíngue e linguisticamente homogêneo e que tem "como consequência o apagamento de subjetividades culturais híbridas [...], tornando-as padronizadas a partir de uma perspectiva etnocêntrica" (ANUNCIAÇÃO, 2018, p. 47). Portanto, o contexto brasileiro exige uma mudança que considere políticas de acolhimento que envolvam a construção de relações interculturais mais inclusivas que acolham as variedades da língua portuguesa. 
Nesse sentido, destaca-se a importância de políticas públicas de acolhimento que englobem o ensino formal dessa língua portuguesa para os migrantes que, de acordo com Milesi e Andrade (2015), possuem necessidades associadas à questão de trabalho e educação, e então o domínio da língua do país de acolhimento assume extrema importância para uma melhor inserção no mercado de trabalho e integração com a comunidade nacional.

Considerando a necessidade de trabalho e a inserção social, Barbosa e São Bernardo (2017) destacam que o conceito de língua de acolhimento vai muito além da simples perspectiva linguística e cultural, pois agrega questões emocionais e subjetivas conflitantes no contato inicial do imigrante com a sociedade que o acolhe. Isso ocorre porque em uma situação de migração forçada nem sempre existe uma afetividade com os aspectos culturais e linguísticos do país de acolhida e, nessa perspectiva, Silva (2012) evidencia que o aprendizado da língua estrangeira pode estar relacionado tanto à afetividade quanto ao instrumentalismo, uma vez que a afetividade está diretamente ligada à construção de identidades e aos fatores culturais que motivam o aprendizado de uma língua, enquanto o aspecto instrumental é muito mais utilitário, vai além do domínio da língua para simples comunicação e torna-se um meio de progressão e aumento das chances na carreira e na mobilidade social.

Além dessas motivações, é preciso considerar também que existem diversos fatores que influenciam a aprendizagem de uma língua estrangeira e, segundo Willis (1996), existem duas variáveis que podem estimular fortemente esse processo: as condições essenciais (exposição, uso e motivação) e as condições desejáveis (instrução formal). Por isso, dentro do contexto migratório, o aprendiz quando não possui o acesso à instrução formal (desejável), desenvolve suas habilidades linguísticas muitas vezes através da conversa informal com as pessoas mais próximas, usando as variedades linguísticas da localidade onde vive e as próprias motivações pessoais para a aprendizagem de acordo com as necessidades do seu cotidiano no trabalho e na vida social.

Os humanos são seres sociais e a língua faz parte de "todas as esferas da atividade humana" (BAKHTIN, 2003, p. 280). Tal fato édestacado por Cassany (1999, p. 142) ao afirmar que "na concepção sociocultural derivada da tese de Vygotsky, linguagem e pensamento têm origem social e se transmitem e se desenvolvem a partir da interação contextualizada entre falantes". Essa interação, segundo Paterson (2012), é um sistema 
V. $11(3)$ 75-89 set-dez 2021

adaptativo complexo que pode ocorrer em três níveis distintos: (i) língua oficial do governo, de um estado-nação em particular, da administração, direito, comércio, educação, mídia de massa, etc.; (ii) língua social ou coletiva de uma comunidade, falada por um grupo de pessoas que vive no mesmo local ou que possui uma característica em comum, além de suas variações regionais, distinções de classe, local de trabalho; (iii) língua idiomática e sua maneira de expressão em tons distintos (mais formal ou mais jargões relacionados ao trabalho).

Em todas essas interações é necessário ter o domínio adequado da língua para participar das práticas de letramento, consideradas "um conjunto de práticas de comunicação social relacionada ao uso da escrita" (SIGNORINI, 2001, p. 97) que permitem à pessoa participar de questões fundamentais como a economia (negócios que são feitos pela escrita), a política (organização e debates) e a sociedade (relações estabelecidas e mantidas em contextos de letramento/letrados).

No contexto migratório, uma das maiores dificuldades enfrentadas pelos recém-chegados é certamente a comunicação e a participação nas questões fundamentais do país de acolhida, principalmente em se tratando dos adultos que precisam se reinserir no mercado de trabalho e aprender rapidamente a língua do país estrangeiro. Apesar da educação ser um direito previsto em lei, as condições para o aprendizado/prática dessa língua em instituições formais de ensino nem sempre são favoráveis, uma vez que, segundo os resultados de uma pesquisa realizada por Marques (2018), das 63 universidade federais brasileiras pesquisadas, somente 14 possuem algum tipo de curso específico para o ensino do português como língua de acolhimento (Plac).

Mesmo diante desse cenário, o aprendizado/prática da língua de acolhimento pode ocorrer em outras condições essenciais, já que, de acordo com Stern (1983), o aprendizado de uma língua depende primordialmente de três fatores: o contexto social; as condições de aprendizagem; e as características dos aprendizes. Já para Oliveira (2010, p. 35, grifo do autor), os "aprendentes que já possuem um background linguístico considerável (o domínio de várias línguas) são potenciais 'bons falantes' da língua a aprender". Essas características demonstram que no processo de acolhida, o contexto afetivo, os meios de aprendizagem e os conhecimentos prévios de uma outra língua são fatores que contribuem positivamente para uma rápida inserção dos migrantes em um novo país. 
Além desses fatores, é preciso considerar as práticas de letramento que ocorrem nos mais distintos meios sociais, em particular as práticas situadas e abordadas por Kleiman (2005, p. 25-26), nas quais "os objetivos, os modos de realizar as atividades, os recursos mobilizados pelos participantes, os materiais utilizados, serão diferentes segundo as características da situação", ou seja, o uso da língua nessas interações é bastante heterogêneo e envolve diversos saberes vinculados à realidade social. Por isso, essas práticas envolvem também diferentes tecnologias como o lápis, papel e as mídias digitais.

No contexto das mídias tecnológicas, Selwyn (2017) destaca que as práticas de comunicação social com o uso da escrita podem ser muito mais plurais com o uso das novas tecnologias, principalmente em se tratando das tecnologias digitais (TD) responsáveis pelo surgimento de comunidades globais que interagem, se comunicam constantemente e quebram a rigidez das fronteiras entre tempo, espaço, indivíduos e instituições.

De acordo com Prensky (2010), o potencial das tecnologias digitais é algo que já está sacramentado entre crianças, jovens e adultos que passam grande parte do tempo online, o que significa que tais recursos encontram-se integrados às vidas das pessoas e as suas atividades cotidianas. Essas tecnologias digitais permitem a utilização de ferramentas importantes no processo de aprendizagem/ prática de uma língua estrangeira, principalmente por meio do uso dos computadores, dos celulares e da internet, uma vez que esses meios ampliam as redes de comunicação e interação entre grupos específicos que compartilham interesses em comum. Segundo Kenski (2012), a ampliação e o uso de determinadas tecnologias se sobressaem à cultura existente e transformam o comportamento individual e coletivo no que se refere à comunicação instantânea e à busca por informações.

Isso ocorre porque ao buscar informações através dos meios digitais, o aprendiz é, então, apresentado a uma nova cultura digital na qual

o corpo, no sentido também mental, é chamado a co-participar e, dessa maneira, co-produzir a obra. Esse fenômeno é muito significativo e importante. Exemplo emblemático é o que acontece no Youtube, ou mesmo nos blogs, e na internet como um todo: temos a possibilidade de gravar músicas, por exemplo, o que favorece um tipo de potencialidade participativa e criativa que não tínhamos, ou, pelo menos, essa participação era infinitamente mais reduzida" (CANEVACCI, 2009, p.12). 
V. $11(3)$

75-89

set-dez

2021
Portanto, o uso das tecnologias digitais nas práticas sociais pode ser considerado uma ferramenta importante para a aprendizagem/ prática da língua de acolhimento ao criar oportunidades de interação com os falantes da língua de acolhida, permitir que o aprendiz participe das questões cotidianas, das discussões políticas e sociais e, acima de tudo, ao reduzir as fronteiras entre tempo, espaço, indivíduos e instituições.

\section{Metodologia}

A partir dos pressupostos teóricos, a pesquisa realizou-se sob a orientação metodológica de cunho qualitativo exploratório, a qual, segundo Godoy, (1995) auxilia a obtenção de dados descritivos sobre pessoas, lugares eprocessos interativos pelo contato direto do pesquisador com a situação estudada, e procura compreender os fenômenos segundo a perspectiva dos participantes da situação em estudo. Essa abordagem, para Calder (1977), é um estímulo ao pensamento científico, que permite o aprofundamento de uma problemática e a possibilidade de gerar novas hipóteses para pesquisas futuras.

A pesquisa foi realizada por meio de um questionário em formato eletrônico que foi compartilhado em onze comunidades virtuais de imigrantes na rede social Facebook: @africanosehaitianosimigrantes, @ francesesnoriodejaneiro, @argentinosenbrasil, @refugiadossiriosnobrasil, @refugiadosnobrasil, @haitianosnobrasil, @russosnobrasil, @ chinesesnobrasil, @venezuelanosnobrasil, @estrangeirosnobrasil, @ italianosnobrasil. Tais comunidades são compostas por seguidores migrantes e refugiados que vivem atualmente no Brasil e que interagem diariamente através de postagens específicas em língua portuguesa.

O período de realização da pesquisa ocorreu entre março e junho de 2020 nos grupos supra delimitados e o questionário contou com dezesseis (16) perguntas, sendo doze (12) delas objetivas que coletavam dados como idade, tempo de permanência no país, onde aprendeu a língua portuguesa, o conhecimento atual da língua portuguesa, o grau de escolaridade, os aspectos que mais chamam a atenção na língua portuguesa, se e como acompanham os noticiários em língua portuguesa, e como e quais os meios tecnológicos utilizam para o aprendizado/prática da língua portuguesa. Além dessas, mais quatro (4) perguntas subjetivas indagavam sobre o país de origem, as principais dificuldades, as preferências dentro da língua portuguesa e quais os idiomas dominam além da língua materna. 
O recorte da pesquisa foi elaborado em função dos objetivos específicos propostos, e a escolha das comunidades se deu após uma pesquisa na rede social Facebook e o envio de um pedido de aceitação, o qual foi concedido pelas onze referidas comunidades, assim como a permissão para a publicação do formulário de pesquisa online. O formulário foi acompanhado por uma mensagem introdutória informando aos seguidores o caráter e o objetivo do estudo, e obtevese então um total de 40 respostas, as quais serão descritas e analisadas a seguir através da interpretação dos dados com base no referencial teórico apresentado.

\section{Resultados da pesquisa}

A primeira parte da pesquisa, composta de informações sobre o perfil dos pesquisados, como faixa etária, país de origem, línguas faladas, grau de escolaridade e o tempo de vivência no Brasil, revelou que a maioria $(51,3 \%)$ tem idade entre $19-30$ anos, ao passo que $41 \%$ estão entre 41-50 anos e 7,7\% entre 51-60 anos. Isso demonstra uma população bastante jovem e em plenas condições laborativas.

Com relação ao grau de escolaridade dos pesquisados, verificase que a maioria $(61,1 \%)$ indica ter frequentado os estudos formais por 14-20 anos, enquanto 20,5\% têm entre 10-13 anos de estudos. Esses dados revelam um contexto migratório de adultos com elevado grau de escolaridade e que precisam aprender a língua portuguesa para se reinserir no mercado de trabalho.

Já em relação ao país de origem, às línguas maternas e às demais línguas nas quais esses migrantes possuem algum tipo de habilidade na escrita, leitura e oralidade, verifica-se a multiculturalidade e o multilinguismo. Isso acontece pois essas pessoas estão inseridas na sociedade através de multipertencimentos, sendo que a maioria dos pesquisados têm como língua materna o espanhol, justamente pela característica migratória brasileira que nos últimos anos tem recebido um fluxo de pessoas provenientes, principalmente, de países latinoamericanos, como Argentina, Bolívia, Colômbia, Venezuela e Uruguai.

Quanto ao panorama das línguas faladas, evidencia-se o fato de que as línguas espanhola e inglesa são recorrentes na maioria dos casos, além da própria língua materna e do português, que é a língua de acolhimento no contexto da pesquisa. É importante observar, ainda, as habilidades dos pesquisados com a língua portuguesa, porquanto 
v. 11 (3)

75-89

set-dez

2021

a maioria (43,6\%) considera seu conhecimento atual intermediário, caracterizado pela leitura, escrita e oralidade com poucos erros. Em contrapartida, 17,9\% apresentam um nível básico de conhecimento da língua com dificuldades na leitura, escrita e oralidade.

Nesse contexto, observamos que as características dos participantes da pesquisa corroboram a prerrogativa de Oliveira (2010) em relação ao fato do background linguístico (o domínio de várias línguas) evidenciar potenciais "bons falantes" da língua de acolhida, uma vez que, estamos tratando de indivíduos com conhecimentos de outras línguas e que declaram ter habilidades intermediárias de leitura, escrita e oralidade em língua portuguesa.

Contudo, é importante destacar que a aprendizagem da língua de acolhida também está relacionada ao tempo transcorrido no país, já que a pesquisa demonstra que a grande maioria dos migrantes $(76,9 \%)$ estão de 1-5 anos no Brasil, enquanto 15,4\% vivem de 6-10 anos no país e 7,7\% entre 11-20 anos, períodos de tempo bastante consideráveis que permitem um certo grau de desenvolvimento linguístico e que certamente habilita-os a ter um conhecimento básico/intermediário da língua portuguesa.

Após analisar o perfil dos pesquisados, partimos para a segunda parte da pesquisa em busca de informações específicas sobre o uso dos meios tecnológicos para o aprendizado/prática da língua portuguesa, destacando as ferramentas utilizadas nesse processo, as afetividades e dificuldades enfrentadas em relação à língua.

O estudo revelou que 20,5\% dos pesquisados afirmam ter aprendido a língua portuguesa no ambiente familiar, 17,9\% em cursos de idiomas, $17,8 \%$ no trabalho, $15,5 \%$ na Internet, 10,3\% em projetos de imigração, 10,3\% em universidades e 7,7\% com amigos. Os dados demonstram a representatividade das instituições sociais como sendo as principais vias de acesso à aprendizagem/prática da língua de acolhimento no contexto nacional e onde o aprendiz adquire aquilo que Paterson (2012) descreve como uma língua social ou coletiva de uma comunidade, falada por um grupo de pessoas que vive no mesmo local ou que possui uma característica em comum, além de suas variações regionais.

Essa característica da língua social que se aprende nos ambientes informais revela o que Willis (1996) acredita ser uma condição essencial de exposição, uso e motivação para o aprendizado de uma nova língua. No entanto, é preciso considerar também as condições 
desejáveis de instrução formal que permitem o acesso à língua oficial do governo que Paterson (2012) descreve como aquela usada pela administração, direito, comércio, educação, mídia de massa, etc., e que permite ao indivíduo participar de questões fundamentais como a economia (negócios que são feitos pela escrita), a política (organização e debates) e a sociedade (relações estabelecidas e mantidas em contextos de letramento/letrados).

Nesse sentido, a pesquisa corrobora Marques (2018) no que diz respeito à necessidade da criação de cursos formais de ensino da língua de acolhida, já que existem poucas instituições no país que oferecem algum tipo específico de ensino do português como língua de acolhimento e os migrantes possuem necessidades reais de inserção no mercado de trabalho e de integração social.

Os pesquisados também foram questionados a respeito dos temas que mais lhe chamam a atenção no contexto da língua portuguesa e $33,3 \%$ citaram a arte e cultura brasileiras, $20,5 \%$ as viagens, $12,8 \%$ a música, $7,7 \%$ a gastronomia, $7,7 \%$ a economia, $5,1 \%$ a religião e $5,1 \%$ a política. 2,6\% os imóveis, enquanto 5,2\% englobaram a arte, cultura, gastronomia e a música em suas preferências. Esses temas foram indicados pelos pesquisados em uma pergunta aberta, o que indica preferências individuais de afetividade com certas características do país de acolhida.

Quando indagados em relação aos meios tecnológicos de comunicação, 66,7\% dos pesquisados dizem acompanhar os noticiários nacionais e internacionais em língua portuguesa e, dentre esses, 64,1\% utilizam o telefone celular, 25,6\% a televisão, 7,7\% o computador e 2,6\% o jornal impresso.

Já quanto ao uso da tecnologia digital para auxiliar a aprendizagem/prática da língua portuguesa, 89,7\% dos sujeitos indicam que costumam utilizá-la frequentemente, sendo que desses, 48,8\% utilizam o telefone celular, $28,2 \%$ a internet, $12,8 \%$ o computador, $5,2 \%$ a televisão digital, 2,6\% os livros eletrônicos e 2,6\% os aplicativos exclusivos de língua portuguesa. Além disso, 66,7\% dos pesquisados afirmam utilizar algum tipo de recurso tecnológico digital para auxiliar o aprendizado e permitir a interação com professores, falantes nativos e/ou com um novo vocabulário da língua de acolhimento. Dentre esses $33,3 \%$ utiliza o aplicativo Duolingo, 28,2\% o Youtube, 20,5\% o Facebook, 7,7\% o Instagram, 5,2\% o Google Tradutor e 5,2\% o aplicativo Volp (vocabulário ortográfico da língua portuguesa). 
v. 11 (3) 75-89 set-dez 2021
Os dados acima revelam a importância dos aplicativos específicos e das redes sociais digitais de comunicação como recursos que permitem a interação em contextos diversos e de acordo com os interesses e necessidades específicas de cada aprendiz. Tal resultado alinha-se à perspectiva de Selwyn (2017), a qual afirma que as práticas de comunicação social com o uso das tecnologias digitais (TD) podem ser mais plurais por permitirem o surgimento de comunidades globais que interagem entre si e quebram as fronteiras entre tempo, espaço, indivíduos e instituições.

Esses dados vão de encontro com as prerrogativas de Prensky (2010) no que tange ao uso sacramentado das tecnologias digitais entre crianças, jovens e adultos que as integram em suas atividades cotidianas, e assim ampliam as redes de interações entre grupos específicos que compartilham interesses em comum, ou seja, neste caso o interesse pelo aprendizado da língua portuguesa.

Além disso, a pesquisa indica outros fatores relacionados ao aprendizado da língua de acolhimento dentro da abordagem de Silva (2012) em relação à afetividade, visto que, na questão subjetiva referente ao que os pesquisados mais gostam da língua, figuram-se as seguintes respostas em ordem de importância: a pronúncia das palavras, a variedade linguística, a sonoridade, a história da língua e a gramática. E, dentre todos os pesquisados, apenas um mencionou o fato de não gostar da língua portuguesa e ter que aprendê-la apenas por necessidade utilitária para poder se inserir no mercado profissional (instrumentalismo).

Os fatores supracitados aparecem na pesquisa como os temas mais admirados na língua portuguesa, no entanto, os sujeitos, ao serem indagados sobre as suas maiores dificuldades com o aprendizado da língua, relatam em ordem de dificuldade: as questões da variedade linguística, a pronúncia de certas palavras, as gírias, a conjugação verbal, a gramática e as regras ortográficas da língua. Isso revela a necessidade de uma instrução formal para que os aprendizes possam dominar a língua e participar das práticas de letramento social relacionadas ao uso da escrita, conforme abordado por Signorini (2001).

Nesse sentido, a análise dos dados nos traz a evidência de que, no grupo pesquisado, o aprendizado da língua portuguesa de acolhimento acontece primordialmente no âmbito das instituições sociais (família, trabalho, internet, amigos, etc.) e em um contexto informal que tem como sistema adaptativo o nível da língua social ou coletiva de uma 
comunidade, a qual, segundo Paterson (2012), é falada por um grupo de pessoas que vive no mesmo local ou que possuem uma característica em comum, além de suas variações regionais, distinções de classe e local de trabalho. Esse aprendizado/prática caracteriza-se pela afetividade, pelo contexto social e pelas condições de aprendizagem que influenciam o desenvolvimento de habilidades comunicativas sociais e que tem nas tecnologias dos aplicativos e das redes sociais digitais grandes aliados que auxiliam no contato com os falantes nativos da língua portuguesa e com uma diversidade de vocabulário e informações que extrapolam o nível da língua coletiva da comunidade na qual esses migrantes estão inseridos.

\section{Considerações Finais}

O presente estudo, ao propor traçar um perfil dos migrantes em relação aos meios tecnológicos utilizados no aprendizado/prática da língua portuguesa, destaca a tecnologia digital (telefone celular, internet, computador, a televisão digital, livros eletrônicos e aplicativos) como um dos principais recursos usufruídos no processo de aprendizagem/ prática da língua de acolhimento, e ressalta questões relativas às dificuldades no aprendizado(gramática e variação linguística) e aos conhecimentos linguísticos prévios desses migrantes que possuem um alto grau de escolaridade em seus países de origem e que falam mais de um idioma além da língua materna.

Os resultados da pesquisa ressaltam também que a aprendizagem/prática da língua portuguesa de acolhimento nem sempre acontece em ambientes formais (escolas, universidades, cursos privados, etc.), mas, em grande parte, no ambiente familiar, no trabalho e na internet, o que destaca o caráter social da linguagem não atrelado diretamente ao estudo da gramática e da sintaxe da língua, mas à oralidade e à interação social fora dos ambientes formais de aprendizagem como escolas e universidades.

Nesse sentido, a presente pesquisa evidencia a carência do ensino formal da língua de acolhimento no país, dado que, ainda são poucas as instituições de ensino que possuem um material específico para atender a esses migrantes, o que demonstra a necessidade de criação de cursos formais de ensino-aprendizagem da língua portuguesa de acolhimento (Plac). Por outro lado, a pesquisa revela a importância do uso das tecnologias digitais no processo de aprendizagem/prática, por 
V. $11(3)$ 75-89 set-dez 2021

permitir aos aprendizes uma maior interação com os falantes nativos da língua e o contato com outras variedades linguísticas.

Portanto, ao levantar esses dados, destacamos a necessidade de outros debates sobre a importância da abertura de cursos formais de acolhida para esses migrantes que chegam ao país, considerando os benefícios das práticas e da inserção da tecnologia digital como uma ferramenta para a aprendizagem/prática. Assim, poderemos proporcionar um ensino que englobe o uso inclusivo das variedades brasileiras da língua portuguesa e que permita ao migrante uma interação com as situações cotidianas reais do uso dessa língua nos mais variados contextos nacionais.

\section{Referências}

ACNUR; FICAS; INSTITUTO MIGRAÇÕES E DIREITOS HUMANOS; MIGRAMUNDO. Migrações, refúgio e apatridia: Guia para comunicadores. São Paulo. $1^{\mathrm{a}}$. ed., 2019. Disponivel em: https://www.acnur.org/portugues/ wp-content/uploads/2019/05/Migracoes-FICAS-color_FINAL.pdf. Acesso em: 20 fev. 2020.

ANÇÂA, M. H. À volta da língua de acolhimento. In: Encontro Regional da Associação Portuguesa de Linguística. 2005, Anais. Setúbal: ESE/Instituto Politécnico de Setúbal, 2005. 1 CD-ROM.

ANUNCIAÇÃO, Renata. F. M. A língua que acolhe pode silenciar? Reflexões sobre o conceito de "Português como Língua de Acolhimento". Revista X, v. 13, n. 1, p.35-56, 2018.

BAKHTIN, M. Os gêneros do discurso. In: BAKHTIN, M. Estética da criação verbal. São Paulo: Martins Fontes, 2003.

BARBOSA, L. M. A; SÃO BERNARDO M. A. Língua de Acolhimento. In: CAVALCANTI, L. et al (Org.). Dicionário Crítico de Migrações Internacionais. Brasília: Editora UnB, 2017.

CALDER, B. J. Focus group and the nature of qualitative marketing research. Journal of Marketing Research. Illinois, v. 14, n. 3, p. 353-364, 1977.

CANEVACCI, M. Comunicação entre corpos e metrópoles. Revista Signos do Consumo. São Paulo, v.1, n.1, p. 8-20, 2009.

CASSANY, D. Construir la escritura. Barcelona: Ediciones Paidós Ibérica, S.A., 1999.

GODOY, A. S. A pesquisa qualitativa e sua utilização em administração de empresas. Revista de Administração de Empresas. São Paulo, v. 35 , n. 4, p.65-71, 1995 .

KENSKI, V. M. Educação e tecnologias: o novo ritmo da informação. 8. ed. Campinas: Papirus Editora, 2012. 
KLEIMAN, A. B. Preciso "ensinar" o letramento? Não basta ensinar a ler e a escrever?. Campinas: Cefiel/IEL/Unicamp, v. 1, 2005.

KUBO, O. M.; BOTOMÉ, S. P. Ensino-aprendizagem: uma interação entre dois processos comportamentais. Interação em Psicologia. Curitiba, v. 5, dez. 2001. Disponível em: https://revistas.ufpr.br/psicologia/article/view/3321/2665. Acesso em: 21 jun. 2021.

MARQUES, A. A. M. Políticas linguísticas e ensino de português como língua de acolhimento para imigrantes no Brasil: uma discussão a partir da oferta de cursos nas universidades federais. 2018. Dissertação (Mestrado em Letras) - Universidade Federal do Rio Grande do Sul (UFRGS), Porto Alegre, 2018.

MILESI, R.; DE ANDRADE, W. C. A sociedade civil na atenção aos imigrantes refugiados - O agir do IMDH. In: DO PRADO, E. J. P.; COELHO, R. (Org.). Migrações e Trabalho. Brasília: Ministério Público do Trabalho, 2015, p. 175202.

OLIVEIRA, A. M. Processamento da linguagem num contexto migratório e de integração. In: GROSSO, M. J. (Org.) Educação em Português e Migrações. Lisboa: Lidel, 2010, p. 30-47.

ORGANIZAÇÃO INTERNACIONAL PARA AS MIGRAÇÕES (OIM). Who's a migrant? Disponível em: https://www.iom.int/who-is-a-migrant. Acesso em: 21 jun. 2021.

PATERSON, A. Language as a Complex Adaptive System. Journal of Akita University, n.67, p. 27-36, 2012.

PRENSKY, M. R. Teaching digital natives: partnering for real learning. California: Corwin press, 2010.

SELWYN, N. Educação e Tecnologia: questões críticas. In: FERREIRA, G. M. S.; ROSADO, L. A. S.; CARVALHO, J. S. (Org.) Educação e Tecnologia: abordagens críticas. Rio de Janeiro: UNESA, p. 85-102, 2017.

SIGNORINI, I. Construindo com a escrita "outras cenas de fala". In: SIGNORINI, I. (Org.). Investigando a relação oral/escrito e as teorias do letramento. Campinas: Mercado de Letras, p. 97-134, 2001.

SILVA, P. M. S. A língua e a cultura portuguesas a Oriente: análise ao caso de Macau. 2012. Tese (Doutorado em Sociologia) - Instituto Universitário de Lisboa (IUL). Lisboa, 2012. Disponível em: http://repositorio.iscte.iul.pt/ hadle/100071/5879. Acesso em: 09 mar. 2020.

STERN, H. H. Fundamental Concepts of Language Teaching. Oxford: Oxford University Press 1983.

UNESCO. Organização das Nações Unidas para a Educação, Ciência e Cultura. Diretrizes de políticas da UNESCO para a aprendizagem móvel. Brasília: UNESCO, 2014. Disponível em: http://unesdoc.unesco.org/images/ 0022/002280/ 228074por.pdf. Acesso em: 10 mar. 2020.

WILLIS, J. A Framework for Task-Based Learning. Essex, England: Addison Wesley Longman Limited, 1996. 